\title{
GERENCIAMENTO DOS RESÍDUOS SÓLIDOS NO MEIO AMBIENTE URBANO: Estratégia para o Desenvolvimento Sustentável com Expansão das Liberdades
}

http://dx.doi.org/10.21527/2176-6622.2020.54.144-153

Recebido em: 7/9/2020

Aceito em: 19/9/2020

Neuro José Zambam

Pós-doutor em Filosofia na Universidade do Vale do Rio dos Sinos (Unisinos). Doutor em Filosofia pela PUCRS. Professor do Programa de Pós-Graduação em Direito da Faculdade Meridional (Imed). Membro do Grupo de Trabalho, Ética e Cidadania, da Associação Nacional dos Programas de Pós-Graduação em Filosofia (Anpof). Coordenador do Centro Brasileiro de Pesquisa sobre a Teoria da Justiça de Amartya Sen: interfaces com direito, políticas de desenvolvimento e democracia. http://lattes.cnpq.br/6893744456793355. https://orcid.org/00000001-5960-4237. neuro.zambam@imed.edu.br; neurojose@hotmail.com

\section{Ana Paula Coelho Abreu dos Santos}

Mestranda em Direito pela Faculdade Meridional (Imed). Integrante do Centro Brasileiro de Pesquisa sobre a Teoria da Justiça de Amartya Sen: interfaces com direito, políticas de desenvolvimento e democracia. Bacharel em Ciências Jurídicas e Sociais pela Universidade de Passo Fundo. Especialista em Direito Constitucional pela Faculdade Damásio. Advogada inscrita na OAB/RS 110.192. http://lattes.cnpq.br/0169976056405965. https://orcid.org/0000-0003-4730-4813. anapcas@gmail.com

\section{RESUMO}

Este artigo tem como objetivo apresentar estratégias de gerenciamento de resíduos sólidos no meio urbano como uma referência para a expansão das liberdades conforme abordado por Amartya Sen. Negligenciar a problemática do inadequado descarte desses resíduos torna o ambiente e a vida humana insustentáveis. O ser humano tem responsabilidade de atuar visando à melhora do ambiente em que vive e de forma ativa constituir parâmetros democráticos em busca de cidades sustentáveis. A democracia é o pressuposto para atingir um modelo de desenvolvimento sustentável. Nesse sentido, Sen ressalta a importância de condições de participação, que ele refere como "capabilities". Assim, a construção de soluções justas e sustentáveis, ou seja, a correta gestão dos resíduos sólidos, com uma ampla participação e responsabilidade social, são decisivos para a legitimidade desse modelo de desenvolvimento. O presente artigo apresentará o desenvolvimento sustentável como um referencial, em que a democracia é o sistema viabilizador. A Lei n. 13.305/2010 (Política Nacional de Resíduos Sólidos) orienta para soluções equitativas ao reconhecer os resíduos sólidos como um bem econômico passível de valor social e provedor de cidadania, emprego e renda, com reflexos relevantes para o exercício da liberdade. A presente análise terá como base o método dedutivo, com o uso de referências bibliográficas.

Palavras-chave: Desenvolvimento sustentável. Democracia. Liberdade. Política nacional de resíduos sólidos. Amartya Sen.

GESTIÓN DE RESIDUOS SÓLIDOS EN EL ENTORNO URBANO:

ESTRATEGIA DE DESARROLLO SOSTENIBLE CON AMPLIACIÓN DE LIBERTADES

\section{RESUMEN}

Este artículo tiene como objetivo presentar las estrategias de manejo de residuos sólidos en el medio urbano como referencia para la expansión de las libertades que aborda Amartya Sen. Descuidar el problema de la disposición inadecuada de estos residuos hace que el medio ambiente y la vida humana sean insostenibles. El ser humano tiene la responsabilidad de actuar para mejorar el entorno en el que vive y de constituir activamente parámetros democráticos orientados a ciudades sostenibles. La democracia es el requisito previo para lograr un modelo de desarrollo sostenible. Sen enfatiza la importancia de las condiciones para la participación, lo que él llama "capabilities". En este sentido, la construcción de soluciones justas y sostenibles, con la correcta gestión de los residuos sólidos, con amplia participación y responsabilidad social, son determinantes para la legitimidad de este modelo de desarrollo. Este artículo presentará el desarrollo sostenible como referencia, en el que la democracia es el sistema habilitador. La Ley no. 13.305/2010 (Política Nacional de Residuos Sólidos) orienta para soluciones equitativas al reconocer los residuos sólidos como un bien económico sujeto a valor social y proveedor de ciudadanía, empleo e ingresos con efectos relevantes para el ejercicio de la libertad. Este análisis se basará en el método deductivo, utilizando referencias bibliográficas.

Palabras-clave: Desarrollo sostenible. Democracia. libertad. Política nacional de residuos sólidos. Amartya Sen.

\section{SUMÁRIO}

1 Introdução. 2 Desenvolvimento sustentável e a perspectiva de Amartya Sen. 3 Expansão das capacidades (capabilities) como estratégia para o desenvolvimento sustentável. 4 Política nacional de resíduos sólidos e o exercício das liberdades em Amartya Sen. 5 Conclusão. 6 Referências. 


\section{INTRODUÇÃO}

Atualmente o ser humano encontra-se inserido cada vez mais no contexto urbano, todavia o crescimento populacional nos centros urbanos acarretou impactos ambientais, de modo que a produção de lixo e seu inadequado descarte tornaram-se um fator que vem alterando a qualidade da vida. Nesse sentido, a problemática gerada pelo inadequado descarte dos resíduos sólidos não deve ser negligenciada.

Nessa perspectiva, o presente artigo tem como objetivo apresentar estratégias de gerenciamento de resíduos sólidos no meio ambiente urbano como uma forma de expansão de liberdades, em que a Lei $n$. 13.305/2010 (Política Nacional de Resíduos Sólidos) converge no que respeita a ser uma resposta de construção justa e sustentável, uma vez que tem como princípio estrutural o desenvolvimento sustentável e a responsabilidade compartilhada de todos os agentes participantes da cadeia dos resíduos sólidos.

Dessa forma, a resposta para essa problemática volta-se para a construção de soluções justas e sustentáveis, constituindo a correta gestão dos resíduos sólidos, com uma ampla participação, conhecimento da legislação e responsabilidade social, decisiva para a legitimidade desse modelo de desenvolvimento. O presente artigo apresentará o desenvolvimento sustentável como um referencial, em que a democracia é o sistema viabilizador.

A democracia é o pressuposto para atingir um modelo de desenvolvimento sustentável. Amartya Sen ressalta a importância de condições de participação, que ele refere como "capabilities", ou seja, esse termo é um aspecto da liberdade substantiva, em que as pessoas devem ter a escolha de levar o tipo de vida que elas valorizam, atentando-se particularmente para a expansão das capacidades.

Ao voltar-se para a construção do adequado gerenciamento dos resíduos sólidos, busca-se olhar a intervenção humana de forma construtiva, perante o meio ambiente, cabendo ao ser humano protegê-lo e melhorá-lo. Tendo em vista a sustentabilidade como um critério a ser seguido, Sen enaltece o Relatório Gro Brundtland, uma vez que este, ao trazer para o público a expressão "Desenvolvimento Sustentável", supera a visão simplista do meio ambiente como "estado de natureza", colocando o ser humano como parte da questão ambiental e indicando a conexão existente para a qualidade de vida.

Ao abordar a sustentabilidade, no entanto, deve-se atentar que esse princípio norteador abrange variadas vertentes, tais como a sustentabilidade ambiental, social, econômica, ética, moral, jurídico-político e cultural, mas, acima de tudo, pressupõe uma responsabilidade intergeracional, em que o desenvolvimento sustentável consiste em uma forma de desenvolvimento que atende às necessidades do presente sem comprometer a capacidade de as futuras gerações atenderem às suas necessidades.

Assim, observar-se-á a aplicabilidade do desenvolvimento sustentável, em que o estabelecimento de um Plano de Gestão adequado tem como pressuposto uma responsabilidade compartilhada de todos os setores da sociedade. Reconhece os resíduos sólidos como um recurso a ser recuperado, consequentemente como um bem econômico passível de valor social, uma vez que possibilita gerar trabalho e renda. Trata-se também de um promotor de cidadania, vindo a trazer reflexos positivos no âmbito social, econômico e ambiental. Para a presente análise utilizar-se-á o método dedutivo, com o uso de referências bibliográficas.

\section{DESENVOLVIMENTO SUSTENTÁVEL E A PERSPECTIVA DE AMARTYA SEN}

A expressão "Desenvolvimento Sustentável" tornou-se o tema condutor da literatura ambiental, expressão esta que ganhou notoriedade por meio do Relatório Brundtland, que traz em seu bojo o conceito de desenvolvimento sustentável para o discurso público.

Dessa forma, Sen e Kliksberg, ao tratarem desse relatório, abordam a definição que este trouxe para a questão do desenvolvimento sustentável:

A necessidade de ação em conjunto foi poderosamente delineada em 1987 no manifesto pioneiro Nosso Futuro em Comum, preparado pela Comissão Mundial sobre Meio Ambiente e Desenvolvimento, liderada por Gro Brundtland. O Relatório de Brundtland definiu desenvolvimento sustentável como aquele que "atende às necessidades do presente sem comprometer a capacidade das futuras gerações de atender às suas próprias necessidades" (2010, p. 64). 
Esse relatório comporta uma importante abordagem sobre as consequências da deterioração dos recursos naturais para o desenvolvimento econômico e social, mostrando-se imprescindível para trazer ao público uma nova visão de conexão do valor do meio ambiente para os seres humanos.

Dessa forma, Amartya Sen enaltece a importância que o relatório de Brundtland trouxe, situando o ser humano como parte da questão ambiental, quando afirma: "O impacto do meio ambiente sobre as vidas humanas precisa estar entre as principais considerações na ponderação do meio ambiente" (2011, p. 282).

O autor também faz uma crítica à visão simplista que muitas vezes é projetada nos discursos do meio ambiente como 'estado de natureza'. Conforme expressa:

O meio ambiente é visto algumas vezes (creio que de forma excessivamente simplista) como o "estado de natureza", incluindo magnitudes como a extensão da cobertura florestal, a profundidade do lençol freático, o número de espécies viventes, e assim por diante. Na medida em que se supõe que essa natureza preexiste permanecerá intacta a menos que a ela adicionemos impurezas e poluentes, pode, portanto, parecer superficialmente plausível que o meio ambiente está mais bem protegido se nele interferirmos o menos possível (SEN, 2011, p. 282).

Nesse prisma, o autor não deixa de frisar a importância que o meio ambiente tem para a qualidade da vida das pessoas e, nesse mesmo aspecto, destaca-se a Constituição Federal Brasileira, em seu artigo 225: "Todos têm direito ao meio ambiente ecologicamente equilibrado, bem de uso comum do povo e essencial à sadia qualidade de vida [...]" (BRASIL, 1988).

Nesse sentido, o autor coloca o ser humano inserido na questão ambiental, uma vez que o equilíbrio do meio ambiente está intrinsecamente ligado à sadia qualidade de vida do ser humano, conforme sua elucidação sobre a temática:

[...] o meio ambiente não é apenas uma questão de preservação passiva, mas também de busca ativa. Ainda que muitas atividades humanas que acompanham o processo de desenvolvimento possam ter consequências destrutivas, também está ao alcance do poder humano enriquecer e melhorar o ambiente em que vivemos. Ao pensarmos nos passos que podem ser dados para conter a destruição ambiental, temos que incluir a intervenção humana construtiva (SEN, 2011, p. 283).

Isso significa pensar no ser humano não o limitando às suas necessidades, mas em seu valor como ser capaz de raciocinar, avaliar, escolher, participar e agir. Como afirma Sen: "[...] as pessoas têm necessidades, mas elas também têm valores [...]" (2011, p. 284).

Entre esses valores, o Relatório Brundtland pontua de forma brilhante a responsabilidade intergeracional: "O desenvolvimento sustentável é o desenvolvimento que encontra as necessidades atuais sem comprometer a habilidade das futuras gerações de atender suas próprias necessidades" (ONU, 1987).

Ou seja, há a responsabilidade de a atual geração se responsabilizar pela qualidade do meio ambiente que as futuras gerações de seres vivos, humanos e não humanos, irão usufruir. Não estão em jogo somente os interesses dos seres humanos, mas uma vez que o ser humano possui maior poder de raciocínio que outras espécies, há maior responsabilidade para com estas.

A perspectiva das obrigações do poder foi apresentada com grande força por Gautama Buda no Sutta-Nipata. Buda diz lá que temos responsabilidade em relação aos animais precisamente por causa da assimetria entre nós, não por causa de qualquer simetria que nos leve à necessidade de cooperar. Ele argumenta, ao contrário, que por sermos muito mais poderosos que as outras espécies, temos uma responsabilidade em relação a elas que se conecta exatamente com essa assimetria de poder (SEN, 2011, p. 239-240).

Dessa forma, o desenvolvimento sustentável tem ligação intrínseca com ações baseadas em valores, em que a sustentabilidade se torna esse valor, norteando a relação do ser humano e o desenvolvimento. Tais ações devem estar atreladas à sustentabilidade ambiental.

\section{EXPANSÃO DAS CAPACIDADES (CAPABILITIES) COMO ESTRATÉGIA PARA O DESENVOLVIMENTO SUSTENTÁVEL}

A democracia tornou-se uma das conquistas da humanidade, constituindo uma forma de organização social das estruturas políticas em diversas sociedades, essencial para o desenvolvimento humano e sustentável. 
Nesse sentido, ao analisar a Conferência da Organização das Nações Unidas referente ao Desenvolvimento Sustentável, sediada no Rio de Janeiro em 2012, conhecida como Rio+20, foram observadas estratégias para a transição ao modelo de desenvolvimento sustentável, em que deveria haver uma espécie de "pacto" entre governo e sociedade para ocorrer o alcance, com a democracia sendo o pressuposto para atingir essa finalidade.

Ao encontro dessa percepção, pontua Zambam:

Uma avaliação segura do desenvolvimento social supõe a afirmação do valor da democracia, independente de precondições, por ser indispensável para a estruturação do modelo de desenvolvimento baseado no princípio da sustentabilidade ao permitir uma ampla rede de relações e debates públicos, da mesma forma que possui um conjunto de instrumentos para auxiliar na organização equitativa das relações sociais internas e externas. Sen $(2000$, p.185) esclarece essa conexão e a sua importância para a estrutura do desenvolvimento. "A importância da democracia reside, como procuramos mostrar, em três virtudes distintas: (1) sua importância intrínseca, (2) suas contribuições instrumentais e (3) seu papel construtivo na criação de valores e normas. Nenhuma avaliação da forma de governo democrático pode ser completa sem considerar cada uma dessas virtudes" (2012, p. 205).

Nota-se, diante da análise do autor, a importância da democracia para a estrutura do desenvolvimento, uma vez que ela aparece como um marco avaliativo da mensuração do desenvolvimento das sociedades. Dessa forma, ao falar sobre o valor moral substantivo da liberdade, o autor aborda a importância da garantia da livre expressão do pensamento, da liberdade de escolha do que as pessoas consideram importantes para a sua realização. Ainda, afirma: “O modelo de desenvolvimento sustentável supõe a existência das condições de participação e de discussão públicas" (ZAMBAM, 2012, p. 206).

Nesse sentido, ao se atentar à necessária estruturação com base na democracia para a transição para uma forma de desenvolvimento que tenha como embasamento o princípio da sustentabilidade, em que o desenvolvimento sustentável acaba por vir como uma possível resposta, entretanto, importante faz-se compreender como José Roberto Marques caracteriza esse princípio:

O princípio da sustentabilidade consiste na necessidade de se limitar qualitativamente o crescimento econômico, com vista à qualidade de vida das atuais e futuras gerações, mantendo-se o equilíbrio ecológico. A sustentabilidade ambiental é uma das vertentes do desenvolvimento sustentável e deve ser conjugada com o crescimento econômico e o progresso social (2010, p. 41-42).

O autor elucida o fato de a sustentabilidade ambiental ser uma das vertentes do desenvolvimento sustentável, vindo a ser conjugada com o crescimento econômico e o progresso social. A expressão "desenvolvimento sustentável" ganhou notoriedade por meio de Gro Brundtland, em 1987, que publicou o relatório inovador 'Nosso Futuro Comum'. Nesse sentido, como bem pontua Giddens:

O Relatório Brundtland reconheceu que o crescimento econômico era necessário para trazer maior prosperidade ao mundo em desenvolvimento. Contudo, o desenvolvimento em geral teria que se tornar sustentável. A Comissão definiu o desenvolvimento sustentável como o "desenvolvimento que atende às necessidades do presente sem comprometer a capacidade de as futuras gerações atenderem as suas necessidades" (2010, p. 87).

Sendo assim, ao pensar formas alternativas de desenvolvimento, a expressão desenvolvimento sustentável vem a público, estando presente na atualidade tanto na literatura ambientalista como também ao se falar em formas de desenvolvimento que vão além da mensuração econômica pelo PIB.

A análise das dimensões da sustentabilidade como meio alternativo de desenvolvimento torna-se primordial. Conforme aponta Juarez Freitas, há pelo menos cinco dimensões da sustentabilidade (dimensão ética, jurídico-política, ambiental, social e econômica). Para o autor, existe uma dialética da sustentabilidade, uma vez que essas dimensões são vinculadas, sendo componentes essenciais do desenvolvimento, como esclarece:

A multidimensionalidade deriva de uma propriedade natural de difícil refutação: o inter-relacionamento de tudo, a conexão inevitável de seres e coisas. Assim, a degradação ambiental, por exemplo, encontra-se associada à degradação social e à criminalidade. E vice-versa. A dimensão jurídica influencia a ética, e assim 
reciprocamente. Noutro modo de dizer, a sustentabilidade (longe de ser unívoca ou unilateral) só pode ser entendida como princípio multidimensional (de raízes biológicas e evolutivas, com desdobramentos sociais, econômicos, éticos e jurídicos), em sentido forte (FREITAS, 2012, p. 72).

Constata-se que desenvolvimento sustentável possui abordagem multidimensional e se entrelaça com o desenvolvimento econômico, ético, social, jurídico, ao passo que a sustentabilidade torna-se um critério norteador para as relações sociais, em que a base para a transição a esse modelo alternativo de desenvolvimento deve estar atrelada à democracia.

Ao abordar essa transição para o desenvolvimento sustentável, destaca Zambam:

Ocorre uma mudança de ordem epistemológica, relacionada com outras concepções político-metodológicas de desenvolvimento, elegendo, em primeiro plano, as prioridades relacionadas com as necessidades humanas, sociais, ambientais e culturais e, também, com os demais aspectos que envolvem esse panorama. Esse novo paradigma não restringe a evolução da sociedade às determinações, necessidades e demandas do progresso econômico, mas submete toda essa rede de relações que constitui a estruturação e a organização da sociedade a uma avaliação, considerando, prioritariamente, o critério de sustentabilidade (2012, p. 136).

Nesse contexto, a sustentabilidade é vista como um critério que submete a rede de relações sociais, a sua estruturação e a organização da sociedade. Ao atentar para o desenvolvimento sustentável, é imperiosa a análise da essencialidade do fortalecimento da democracia, uma vez que o desenvolvimento sustentável supõe a existência de condições de participação e de discussão pública.

A importância de condições de participação, conforme propõe Sen, perpassa o que ele desenvolve como "capabilities". Ou seja, esse termo é um aspecto da liberdade substantiva, em que as pessoas devem ter a escolha de levar o tipo de vida que elas valorizam, destacando-se que o autor atenta-se particularmente para a expansão das capacidades (capabilities), podendo vir a expandir-se por meio de políticas públicas, ou a própria direção da política pública pode vir a ser influenciada pelo uso efetivo das capacidades participativas do povo (SEN, 2010, p. 33).

A expansão das capabilities vem a pressupor dois aspectos distintos, o aspecto do processo e o aspecto da oportunidade:

A privação de liberdade pode surgir em razão de processos inadequados (como a violação do direito ao voto ou de outros direitos políticos ou civis), ou de oportunidades inadequadas que algumas pessoas têm para realizar o mínimo que gostariam (incluindo a ausência de oportunidades elementares como a capacidade de escapar da morte prematura, morbidez evitável ou fome involuntária) (SEN, 2010, p. 32).

Sendo assim, são essenciais processos adequados, que visem à participação, bem como oportunidades sociais que forneçam a estrutura para que o indivíduo possa ter o ato da escolha, como expõe Zambam: "a falta das capabilidades ${ }^{1}$ corresponde à privação da liberdade" (2012, p. 105).

Ainda, as condições de escolha das pessoas são imprescindíveis para que estas venham a atuar como agentes, ou como define Sen: "Agency Aspect", sendo alguém que age ou ocasiona mudança.

Dessa forma, torna-se imprescindível fazer a distinção do que seja "aspecto do bem-estar" (well being aspect) e o "aspecto da condição de agente" (Agent aspect). O primeiro são as oportunidades e realizações do indivíduo, já o segundo vai além do bem-estar individual, como bem argumenta Sen:

O "aspecto do bem-estar" é particularmente importante na avaliação de questões de justiça distributiva (incluindo o diagnóstico da injustiça econômica) e na avaliação da natureza do "quinhão" que cabe à pessoa em termos de vantagem individual. $O$ "aspecto da condição de agente" contém uma visão mais abrangente da pessoa, incluindo a valorização de várias coisas que ela gostaria que acontecessem e a capacidade de formar esses objetivos e realizá-los (2017, p. 75).

ZAMBAM (2012, p. 98) faz a opção pelo termo "capabilidade", em que compreende a presença da pessoa como agente ativo, ao invés de capacidade ou capacitações, como ocorre em diversas traduções e referências, pois tem como objetivo entender a importância e o alcance dessa expressão fundamental no pensamento de Sen. 
Assim sendo, a sustentabilidade compreende o ser humano como parte da questão ambiental, em que o desenvolvimento sustentável só vem a ser possível por meio do sistema democrático. Tal sistema é fortalecido pela expansão das capabilities promovidas por políticas públicas, ou mesmo estas políticas públicas podem ser influenciadas pelo uso efetivo das capacidades da população. Ou seja, tem-se a intervenção humana construtiva, como agente capaz de raciocinar, avaliar, escolher, participar e agir construtivamente perante o meio ambiente.

\section{POLÍTICA NACIONAL DE RESÍDUOS SÓLIDOS E O EXERCÍCIO DAS LIBERDADES EM AMARTYA SEN}

A população humana está inserida em diversos ecossistemas, com a sua inserção na vida urbana sendo uma realidade que ganhou grandes proporções. Esse crescimento populacional nos centros urbanos, todavia, trouxe impactos ambientais, por exemplo, a produção de lixo e seu inadequado descarte é um fator que altera a qualidade da vida nesse ecossistema urbano.

Nesse sentido, o estudo do meio ambiente urbano e como se dão as políticas voltadas ao gerenciamento dos resíduos sólidos torna-se urgente, uma vez que o inadequado descarte dos resíduos sólidos resulta em uma barreira para alcançar o desenvolvimento de cidades sustentáveis.

Dessa forma, para contextualizar tais afirmativas é imprescindível analisar os estudos trazidos por Dias:

As cidades são ecossistemas criados pelos seres humanos. Apesar de ocupar apenas $2 \%$ da superfície da Terra, as cidades consomem $75 \%$ dos recursos naturais globais e produzem $80 \%$ da poluição. Na atualidade, a maioria das pessoas já vive em ecossistemas urbanos, constituindo-se no hábitat preferido da espécie humana (2009, p. 19).

Como exposto, o consumo de recursos naturais e a poluição que produzem as cidades são preocupantemente elevados. Sendo assim, ao estudar formas de manutenção do equilíbrio ambiental não se deve negligenciar o ecossistema urbano e seu impacto no meio ambiente.

Ao adentrar na análise do meio ambiente urbano, não há como não conectar com a realidade da produção e consumo. A Agenda 21, Capítulo $4,{ }^{2}$ chama a atenção para os padrões de consumo, e, consequentemente, para os modelos de produção, uma vez que se estimulam entre si.

Nesse sentido, o alinhamento do desenvolvimento com a produção e o consumismo inconsequente reflete no aumento notório do lixo, uma vez que no que diz respeito à produção, se houvesse um maior emprego de tecnologias limpas que implicassem menos consumo de matérias e energia, geraria menor produção de resíduos com maior capacidade de seu reaproveitamento e com menor volume para a sua disposição final (MILARÉ, 2018).

Ainda, ao sopesar o que sejam o consumo e o consumismo, o primeiro pode contribuir claramente para o desenvolvimento humano, aumentando as suas capacidades, sem afetar adversamente o bem-estar coletivo. Por outro lado, o consumismo consiste numa mentalidade arraigada a hábitos mórbidos, mais ou menos compulsivos (MILARÉ, 2018).

Dessa forma, as necessidades humanas não devem estar em contraposição com as necessidades do planeta Terra, devendo ter como pressupostos a produção e o consumo sustentável, a fim de poder efetivar o processo de desenvolvimento sustentável.

Isso posto, torna-se necessário fazer uma diferenciação do que vem a ser resíduos sólidos, como bem pontua Édis Milaré:

Todo material, substância, objeto ou bem descartado resultante de atividades humanas em sociedade, a cuja destinação final se procede, se propõe a proceder nos estados sólido ou semissólido, bem como gases contidos em recipientes líquidos cujas particularidades tornem inviável o seu lançamento na rede pública de esgotos ou em corpos d'água, ou exijam para isso soluções técnica ou economicamente inviáveis em face da melhor tecnologia disponível (2015, p. 769).

4.4. Como parte das medidas a serem adotadas no plano internacional para a proteção e a melhora do meio ambiente é necessário levar plenamente em conta os atuais desequilíbrios nos padrões mundiais de consumo e produção. 


\section{O autor elucida sobre o significado de rejeitos:}

Resíduos sólidos que, depois de esgotadas todas as possibilidades de tratamento e recuperação por processos tecnológicos disponíveis e economicamente viáveis, não apresentam outra possibilidade que não a disposição final ambientalmente adequada (MILARÉ, 2015, p. 748).

O autor explicita tecnicamente que resíduos sólidos têm como premissa ser o objeto descartado proveniente das atividades humanas, no entanto o destino final dado aos resíduos nem sempre foi motivo de preocupação da sociedade. Por exemplo, no ano de 2011 apenas $8 \%$ dos 5.565 municípios brasileiros possuíam programas de coleta seletiva, realidade esta que persistiu e persiste, embora haja políticas ambientais e outras normas regulamentando o descarte e o controle de materiais poluentes (BARBOSA; IBRAHIN, 2019, p. 16).

Barbosa e Ibrahin trazem mais dados sobre essa temática:

Já segundo a Associação Brasileira de Resíduos Sólidos e Limpeza Pública (ABLP), apenas $40 \%$ do lixo domiciliar separado pela população é coletado seletivamente pelos serviços de coleta pública, e, desse montante, apenas 30 a $40 \%$ são encaminhados a aterros sanitários adequados. Ainda de acordo com os dados da ABLP, os volumes dos resíduos descartados enviados para as indústrias de transformação alcançam índice de menos de $2 \%$ de materiais reciclados, conforme os dados recolhidos nos anos 2008/2009 [...] (2019, p. 16).

Torna-se, então, evidente a importância de instrumentos de gestão ambiental para melhorar esses resultados. Foi nesse sentido que em agosto de 2010 foi aprovada a Política Nacional dos Resíduos Sólidos (PNRS), legislada por meio da Lei n. 13.305/2010. Essa aprovação teve como marco o início de uma forte articulação dos três entes Federados - União, Estados e municípios. O objetivo foi encontrar soluções para a problemática do gerenciamento dos resíduos sólidos.

Um dos pontos centrais da PNRS está na corresponsabilidade ou responsabilidade compartilhada, em que esta é definida legalmente entre todos os agentes participantes da cadeia de resíduos sólidos. Isto é, para além do encargo dos entes públicos, vem tornar responsáveis os demais geradores dos resíduos sólidos, pessoas físicas ou jurídicas que venham a gerar resíduos por meio de suas atividades, nelas incluído o consumo.

Em outras palavras:

Como é previsto na PNRS, a corresponsabilidade é questão central na limpeza urbana, ao chamar a atenção para o fato de que não é apenas o governo o responsável pela gestão dos resíduos, mas a sociedade como um todo. A maior participação da sociedade colabora para a mudança da lógica de que uma cidade limpa é aquela que você mais limpa para dar lugar ao conceito de que, na verdade, uma cidade limpa é aquela que menos se suja. Essa mudança de consciência possibilita o desenvolvimento da sociedade em relação ao tema, isto é, os resíduos deixam de ser vistos como rejeitos e passam a ser vistos como recursos a serem recuperados (ASSOCIAÇÃO..., 2016, p. 17).

A instituição de um Plano de Gestão adequado tem como pressuposto responsabilidade compartilhada de todos os setores da sociedade, de forma que se faz necessária uma mudança de consciência em relação aos resíduos sólidos, passando a vê-los não como rejeitos, mas como recursos a serem recuperados, o que, se assim for reconhecido, importa também em tê-los como um bem econômico passível de valor social, uma vez que vem a gerar trabalho, renda, revelando-se um promotor de cidadania e trazendo reflexos positivos no âmbito social, ambiental e econômico.

Sendo assim, a percepção dos resíduos sólidos como passível de valor econômico e os reflexos positivos que podem vir a gerar, como fruto de uma correta gestão, e em consequência a expansão da liberdade de agentes sociais, converge com o que propõe Amartya Sen:

[...] o crescimento econômico não pode sensatamente ser considerado um fim em si mesmo. O desenvolvimento tem de estar relacionado sobretudo com a melhora da vida que levamos e das liberdades que desfrutamos. Expandir as liberdades que temos razão para valorizar não só torna a vida mais rica e mais desimpedida, mas também permite que sejamos seres sociais mais completos, pondo em prática nossas volições, interagindo com o mundo em que vivemos e influenciando esse mundo (2010, p. 29). 
Sen elucida o que o desenvolvimento deve representar, indo além de um crescimento econômico mensurado pelo Produto Nacional Bruto. Para ele, deve representar uma melhora qualitativa na vida das pessoas. Nesse sentido, a Política Nacional de Resíduos Sólidos visa a trazer reflexos positivos nos âmbitos social, ambiental e econômico, se os resíduos sólidos forem manejados de forma adequada. Destaca-se, ainda, o fato de essa legislação ter como pilar o desenvolvimento sustentável.

Dessa forma, torna-se imprescindível pensar alternativas de desenvolvimento, com o desenvolvimento sustentável constituindo-se uma delas, cabendo ao ser humano "a responsabilidade de arquitetar, conduzir e executar o processo de desenvolvimento sustentável” (ZAMBAM, 2012, p. 145).

Como expressa Neuro José Zambam:

A importância da qualidade da vida humana é central para o processo de desenvolvimento sustentável, tanto pela sua razão instrumental, que tem como objetivo a transformação do modelo vigente, quanto pelo valor intrínseco da pessoa. Uma sociedade que se preocupa em efetivar, pela prioridade em investimentos, a promoção das condições de vida de seus habitantes, melhorando a qualidade e o acesso ao sistema educacional, o aprimoramento das condições dos programas de saúde e a implementação de outros programas de promoção humana, como, por exemplo, o incentivo a geração de emprego e renda, tem clareza sobre a importância do capital humano para o processo de desenvolvimento como um todo $(2012$, p. 149).

A sustentabilidade vem a englobar valores que norteiam a sociedade e o bem público, pois abrange a sustentabilidade econômica, social e ambiental, possuindo cunho universal, ou seja, todas essas searas vêm a impactar a qualidade de vida do ser humano, esta considerada o aspecto central para o processo de desenvolvimento sustentável. Assim, há a possibilidade de um cunho universal, pois não tem qualquer base ideológica ou religiosa, e está estruturada na responsabilização de desenvolvimento ético e moral das presentes gerações com as futuras.

A gestão adequada dos resíduos sólidos, portanto, alicerçada em diretrizes como a Política Nacional de Resíduos Sólidos, uma vez que esta tem como princípio a responsabilidade compartilhada, bem como o desenvolvimento sustentável, pode refletir na expansão das liberdades dos agentes sociais. Os resíduos sólidos são reconhecidos como um bem econômico, e podem abrir novos mercados, gerar trabalho, emprego e renda, conduzir à inclusão social, além de diminuir os impactos ambientais causados pelo seu inadequado descarte.

\section{CONCLUSÃO}

Com o presente estudo foi possível concluir que se faz urgente um novo modelo de desenvolvimento sustentável, revelando-se a democracia um pressuposto para a sua aplicação, uma vez que este envolve a discussão pública para atender às necessidades da sociedade por desenvolvimento social, econômico, com base na proteção ambiental.

Constatou-se também a importância do Relatório Gro Brundtland, que trouxe notoriedade para o tema do desenvolvimento sustentável, expressão esta que segundo Amartya Sen é de extrema relevância, pois coloca o ser humano como parte da questão ambiental. Apesar de muitas das atividades humanas ao longo dos tempos terem sido e continuarem sendo prejudiciais ao meio ambiente, também está ao alcance do ser humano pensar formas de melhorar o meio ambiente e protegê-lo, ou seja, o autor fala de uma intervenção humana construtiva com relação ao meio ambiente.

Nesse sentido, percebeu-se a necessidade de pensar formas de desenvolvimento, que atualmente tem como base a produção e o consumo de mercadorias tornando-se insuficiente e prejudicial ao equilíbrio ambiental e, consequentemente, à qualidade de vida.

Diante do exposto, ao analisar o meio ambiente urbano e sua acessibilidade aos mais diversos bens de consumo, bem como a presença de indústrias, notou-se o excesso de produção de lixo como reflexo dessa forma de desenvolvimento, com o seu inadequado descarte constituindo um fator problemático no ecossistema urbano, que traz consequências como doenças, poluição de rios e mares. Ou seja, o descarte inadequado de resíduos sólidos é uma das principais fontes de poluição. 
Sendo assim, o desenvolvimento sustentável passa a ser um princípio norteador, estando presente na atualidade tanto na literatura ambientalista como ao se falar em formas de desenvolvimento que vão além da mensuração econômica pelo PIB. Há amparo nos mais variados textos legais como um princípio base, como é o caso da Lei n. 13.305/2010, que trata da Política Nacional de Resíduos Sólidos.

Ficou clara a importância dessa lei, que tem como princípio estrutural o desenvolvimento sustentável e a responsabilidade compartilhada de todos os agentes participantes da cadeia dos resíduos sólidos. Estes agentes são os entes públicos e os demais geradores dos resíduos sólidos, pessoas físicas e jurídicas, que venham a gerar resíduos por meio de suas atividades, nelas incluído o consumo.

Por fim, essa normativa reconhece os resíduos sólidos como um bem econômico passível de valor social, uma vez que podem gerar trabalho, renda, promover cidadania, trazer reflexos positivos nos âmbitos social, ambiental e econômico. Em outras palavras, ela converge com a visão sobre o desenvolvimento de Amartya Sen, pois é um bem passível de expandir as liberdades, ou seja, amplia as condições de escolha das pessoas de levarem o tipo de vida que valorizam, bem como de suas ações como agentes (Agency Aspect), sendo alguém que age ou ocasiona a mudança.

Nesse sentido, ao pensar estratégias que visem a efetivar o desenvolvimento sustentável, é imprescindível o fortalecimento da democracia, uma vez que tem como pressuposto promover condições de participação e de discussão pública. Isto é, o ser humano como parte da questão ambiental, como agente capaz de raciocinar, avaliar, escolher, participar e agir construtivamente. As necessidades e demandas do progresso econômico, bem como a rede de relações e a organização da sociedade, devem considerar a sustentabilidade como critério de sua estruturação.

\section{REFERÊNCIAS}

ASSOCIAÇÃO BRASILEIRA DE RESÍDUOS SÓLIDOS E LIMPEZA PÚBLICA. Índice de Sustentabilidade da Limpeza Urbana para os Municípios Brasileiros. Disponível em: http://www.ablp.org.br/pdf/SELUR-ISLU-2016-ACESSIBILIZADO1.pdf. Acesso em: 10 fev. 2020.

BARBOSA, Rildo Pereira; IBRAHIN, Francini Imene Dias. Resíduos sólidos - impactos, manejo e gestão ambiental. São Paulo: Saraiva, 2019.

BRASIL. Constituição Federal. 1988. Disponível em: http://www.planalto.gov.br/ccivil_03/constituicao/constituicao.htm. Acesso em: nov. 2019.

BRASIL. Política Nacional sobre Resíduos Sólidos. Disponível em: http://www.planalto.gov.br/ccivil_03/_ato2007-2010/2010/ lei/I12305.htm Acesso em: dez. 2020.

BRUNDTLAND, Gro. Comissão Mundial sobre Meio Ambiente e Desenvolvimento - Nosso Futuro em Comum. Disponível em: https://edisciplinas.usp.br/pluginfile.php/4245128/mod_resource/content/3/Nosso\%20Futuro\%20Comum.pdf. Acesso em: fev. 2020.

DIAS, Generaldo Freire. Atividades interdisciplinares de educação ambiental. São Paulo: Gaia, 2009.

FREITAS, Juarez. Sustentabilidade. Direito ao futuro. Belo Horizonte: Fórum, 2012.

GIDDENS, Anthony. A política da mudança climática. Trad. Vera Ribeiro. Rio de Janeiro: Zahar, 2010.

MARQUES, José Roberto. Lições preliminares de Direito Ambiental. São Paulo: Editora Verbatim, 2010.

MILARÉ, Édis. Direito do ambiente. 11. ed. São Paulo. Thompson Reuters, 2018.

MILARÉ, Édis. Dicionário de direito ambiental. São Paulo: Editora Revista dos Tribunais, 2015.

NAÇÕES UNIDAS. A ONU e o meio ambiente. Disponível em: https://nacoesunidas.org/acao/meio-ambiente/. Acesso em: 16 jun. 2019a.

NAÇÕES UNIDAS. Declaração da Conferência das Nações Unidas sobre o Meio Ambiente Humano - 1972. Disponível em: https://www.apambiente.pt/_zdata/Politicas/DesenvolvimentoSustentavel/1972_Declaracao_Estocolmo.pdf. Acesso em: 16 jun. 2019.

NAÇÕES UNIDAS. Relatório da Comissão Mundial sobre Meio Ambiente e Desenvolvimento. Disponível em: https://www. un.org/documents/ga/res/42/ares42-187.htm. Acesso em: 19 jun. 2019b.

ONU. ORGANIZAÇÃO DAS NAÇÕES UNIDAS. Contribuições para a Conferência Rio +20. 1987. Disponível em: file:///C:/Users/ AnaPaula/Downloads/Acordo\%20para\%200\%20Desenvolvimento\%20Sustent\%C3\%A1vel\%20-\%20Rio\%2020\%20-\%20 20111006-1.pdf. Acesso em: 3 jan. 2020.

SEN, Amartya. A ideia de justiça. Trad. Denise Bottmann e Ricardo Doninelli Mendes. São Paulo: Companhia das Letras, 2011. 
SEN, Amartya; KLIKSBERG, Bernardo. As pessoas em primeiro lugar - a ética do desenvolvimento e os problemas do mundo globalizado. Trad. Bernardo Ajzemberg e Carlos Eduardo Lins da Silva. São Paulo: Companhia das Letras, 2010.

SEN, Amartya. Desenvolvimento como liberdade. Trad. Laura Teixeira Motta. São Paulo. Companhia das Letras, 2010.

SEN, Amartya. Sobre ética e economia. Tradução Laura Teixeira Motta. São Paulo. Companhia das Letras, 2017.

ZAMBAM, Neuro José. Amartya Sen - liberdade, justiça e desenvolvimento sustentável. Passo Fundo: Imed Editora, 2012. 